\title{
Support vector machine based fault section identification and fault classification scheme in six phase transmission line
}

\author{
A. Naresh kumar ${ }^{1}$, M. Suresh Kumar ${ }^{2}$, M. Ramesha ${ }^{3}$, Bharathi Gururaj ${ }^{4}$, A. Srikanth ${ }^{5}$ \\ ${ }_{1,5}$ Department of Electrical and Electronics Engineering, Institute of Aeronautical Engineering, Hyderabad, India \\ ${ }^{2}$ Department of Aerospace Engineering, Sandip University, Nashik, India \\ ${ }^{3}$ Department of Electronics and Communication Engineering, GITAM (Deemed to be University), Bengaluru, India \\ ${ }^{4}$ Department of Electronics and Communication Engineering, ACS College of Engineering, Bengaluru, India
}

\begin{tabular}{l}
\hline \hline Article Info \\
\hline Article history: \\
Received Apr 4, 2021 \\
Revised Jul 24, 2021 \\
Accepted Aug 21, 2021
\end{tabular}

Keywords:

Faults

Six phase transmission system

Support vector machine

\begin{abstract}
The higher complexity of a six phase transmission system (SPTS) construction and the large number of possible faults makes the protection task challenging. Moreover, the reverse \& forward path faults in SPTS cannot be detected by traditional relay as it becomes under-reach. In this paper, a support vector machine (SVM) method including Haar wavelets for SPTS fault section identification and fault classification is focused. The positivesequence component phase angle and currents at middle two buses are used to formulate a suggested method. Feasibility of suggested SVM is tested with a $138 \mathrm{kV}, 300 \mathrm{~km}, 60 \mathrm{~Hz}$, SPTS in MATLAB based Simulink platform. Several major parameters including far end and near end location conditions are taken to investigate the reach setting and accuracy of proposed SVM. This relaying method can detect the existence of fault in reverse \& forward path in $1 \mathrm{~ms}$ time.
\end{abstract}

This is an open access article under the CC BY-SA license.

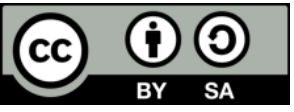

Corresponding Author:

A Naresh Kumar

Department of Electrical and Electronics Engineering

Institute of Aeronautical Engineering

Hyderabad, 500043, Telangana, India

Email: ankamnaresh29@gmail.com

\section{INTRODUCTION}

Electricity has become the universal driver for social economic developments. Due to urban growth as well as constraints on right-of-way, there are limits on installing latest transmission line. Recently, six phase transmission system (SPTS) is being employed to improve the transmission reliability and capacity [1], [2]. SPTS must be equipped with the relays to ensure continuous monitoring for detect faults. Thus, SPTS is restored to the normal condition and power supply is reconnected for load costumers in the lowest possible time leading to high reliability. A considerable amount of literature required to study with the complication of a fault section identification and fault classification method. To ensure accurate and faster detection of SPTS disturbances, different monitoring schemes have been presented by researchers.

Researchers over the world wide have widely studied [3], [4] different features of SPTS viz. lower audible noise levels, decreased radio interference levels, lesser corona, reduced conductor surface gradient, higher efficiency, good voltage regulation, thermal loading capacity and better surge impedance loading. Some recent papers reveal that SPTS performs excellently in obtaining a high power transmission capacity. Published fault statistics [5]-[7] clearly divulge that a majority of SPTS faults are shunt faults. In the past decade many researchers focused many methodologies for fault location in a SPTS. Researchers made a work on fuzzy method to get the faulty location [8], [9] for a SPTS. Further, a research work [10], [11] has been done 
with real-time validation for solving fault issues in SPTS by Sunil K et al. Another scheme by Ebha et al. [12], [13] implemented artificial neural network to predict the faults in SPTS.

Section identification/discrimination/directional relaying and classification have been a hot topic for few decades. Researchers have exerted much effort over the years exploring relaying and classification [14][17]. Additionally, various challenges have been reviewed in SPTS with relaying and classification [18], [19]. Although the aforesaid schemes, remarkably, contributed in the directional relaying, the emergence of new structures along with complexity of SPTS has necessitated the usage of intelligent techniques in the directional relaying. A suitable and straightforward method based on support vector machine (SVM) with relaying and classification in [20]-[25] for directional relaying. It is observed from literature survey that no paper exploited the directional relaying in SPTS using SVM. In this context, a maiden attempt has been done in this paper to present a SVM as SPTS faulted line discrimination and faulty phase identification issues. The main aims of this paper are: i) Studying the faults in three sections, ii) Developing of SVM-based for directional relaying and classification methods in SPTSA smaller amount computing work, iv) Detection of the faults unambiguously, and v) Enhancement of reach setting and accuracy.

The article starts with introduction followed by the review of current research work is presented. Next, it gives the SPTS details. After that, it develops the SVM model and it's designing. Sequentially, the experimental results are presented and the concluding remarks are provided.

\section{SYSTEM STUDIED}

The proposed support vector machine (SVM) based protection relaying has been implemented for a SPTS referring to the Springdale-McCalmont $138 \mathrm{kV}, 60 \mathrm{~Hz}$ line of $300 \mathrm{~km}$ length is shown in Figure 1. The source impedances of sending terminal and receiving terminal are $2.02+\mathrm{j} 9.03 \Omega$ and $4+\mathrm{j} 17.88 \Omega$, respectively. The circuit of SPTS is implemented in MATLAB based Simulink platform using distributed parameter lines and its details are shown in Table 1. The specifications of the SPTS have been adopted in this work for simulating. Phase angle of positive-sequence component, zero-sequence component and Haar wavelet currents in SPTS during faulty condition in section-1 are in illustrated Figures 2-4, respectively. The outline of suggested SVM-based directional relaying and classification schemes for shunt faults is exemplified in Figure 5.

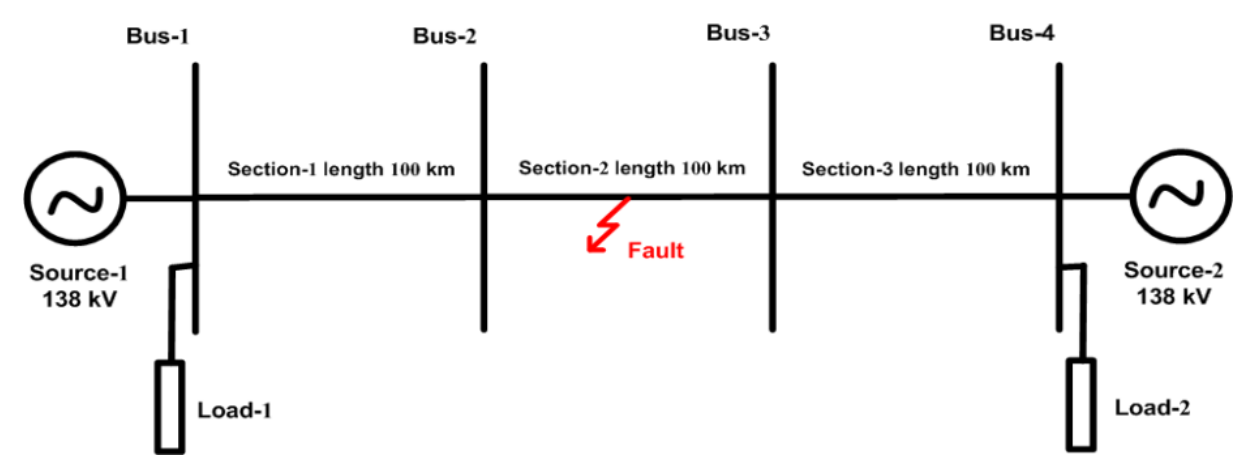

Figure 1. SPTS

Table 1. SPTS parameter values

\begin{tabular}{lcc}
\hline Parameter & Units & Values \\
\hline Number of Circuits & - & 1 \\
Number of Sections & - & 3 \\
Number of Phases & - & 6 \\
Source Voltage & {$[\mathrm{kV}]$} & 138 \\
Base Power & {$[\mathrm{MVA}]$} & 120 \\
Frequency & {$[\mathrm{Hz}]$} & 60 \\
Earth Resistivity & {$[\Omega-\mathrm{m}]$} & 150 \\
Line Length & {$[\mathrm{km}]$} & 300 \\
Short Circuit Capacity $[\mathrm{MVA}]$ & - & 1350 \\
Source X/R Ratio & - & 9 \\
Load at Bus & {$[\mathrm{kW}]$} & 120 \\
& {$[\mathrm{kVAR}]$} & 120 \\
\hline
\end{tabular}

Int J Artif Intell, Vol. 10, No. 4, December 2021: 1019 - 1024 


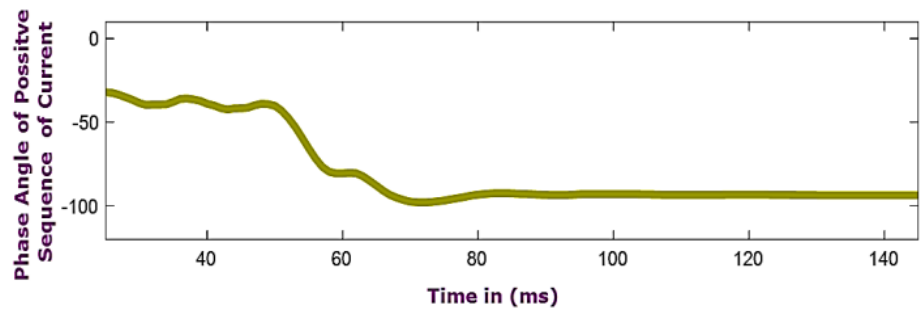

Figure 2. Phase angle of positive sequence component in SPTS during faulty condition

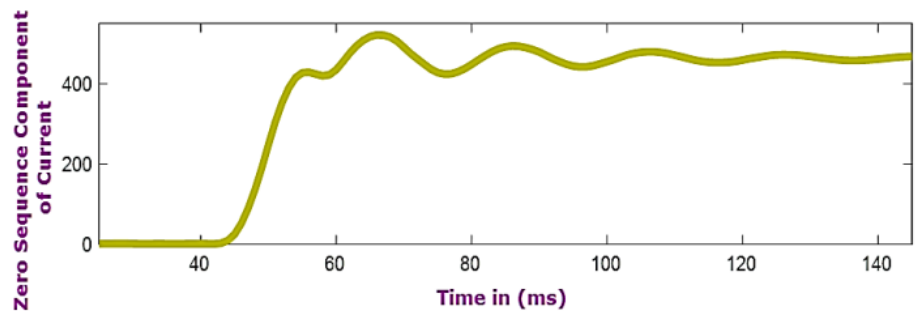

Figure 3. Zero sequence component of current of SPTS during faulty condition

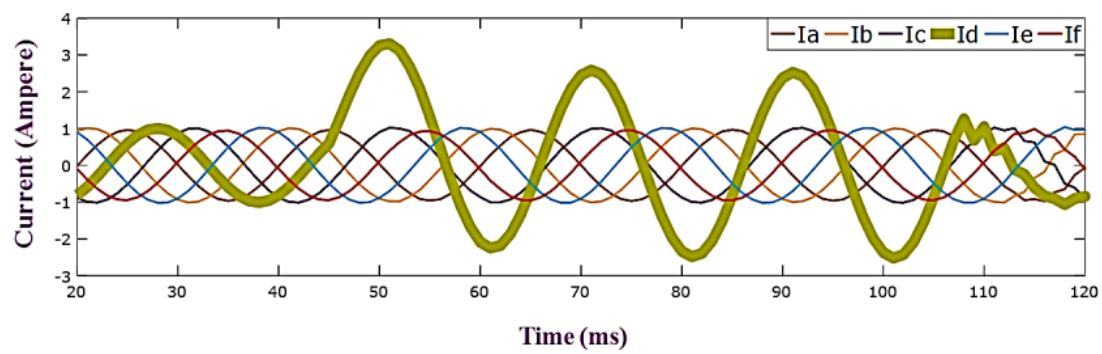

Figure 4. Haar wavelet currents of SPTS during faulty condition

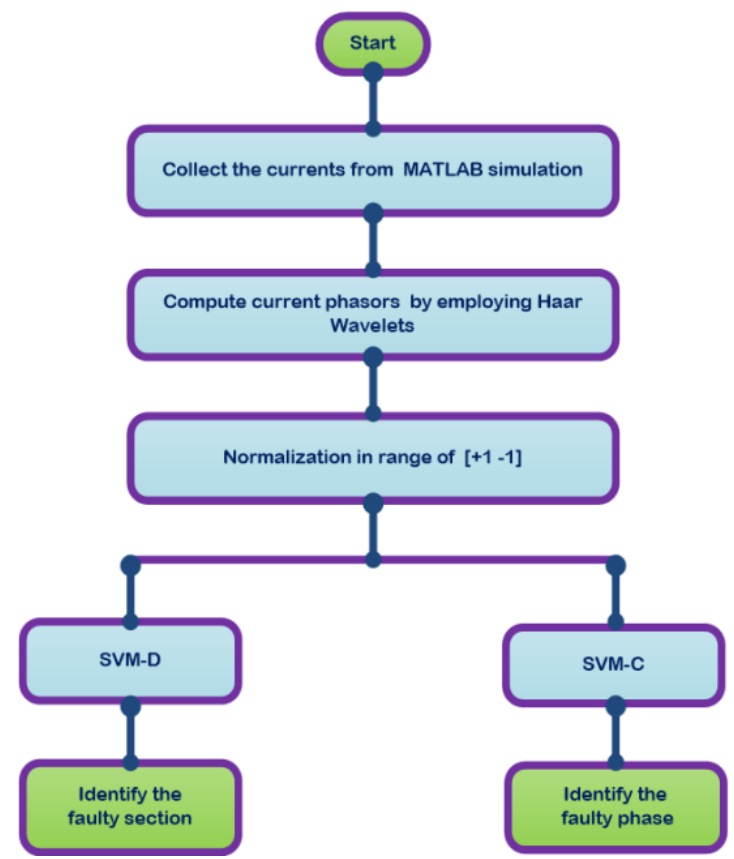

Figure 5. Flow of proposed work 


\section{TECHNIQUE USED}

The support vector machine (SVM) is developed from the theory of statistical learning concepts in late 1960 s. Recently, SVM has emerged as a popular tool for solving the regression and classification problems. It deals primarily with two class classification issues. A hyperplane or linear line is built as decision boundary between feature data sets of two-classes for classification. The nearest feature data points to the hyperplane are known as support vectors. The two class data point with the separating linear line is depicted in Figure 6. Meanwhile, support vector regression can be employed to determine a function which approximates the mapping function from an input domain to another domain of real values based on training data set while maintaining all main features that exemplify the maximum margin method. In this section, linear support vector machine based technique for classification of shunt faults in a SPTS is discussed.

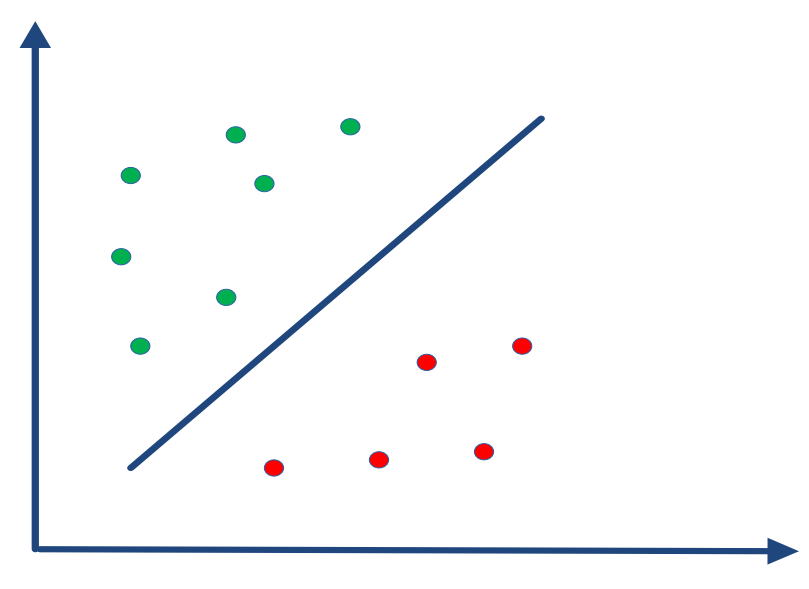

Figure 6. Linear SVM

For the protection two SVM have been designed namely SVM-D and SVM-C to identify the fault section identification and fault classification, respectively. The positive-sequence component phase angle and Haar wavelet currents is used to study the faults in a SPTS. The obtained samples of the currents and positive-sequence component phase angle are classified into large range of frequencies using Haar wavelets. After that, from the $3^{\text {rd }}$ level coefficients are extracted. The total number feature sets are 184 features. Additionally, to scale feature sets, normalization is completed between -1 and +1 therefore it can appropriately be compared. The feature data is then created for training as well as testing process considering different of simulated conditions viz. fault types, fault section, the fault resistance, fault instant, and fault distance.

Few features cannot predict the output perfectly from the total feature data set. Consequently the prediction accuracy decreases. Thus to enhance the accuracy, redundant feature data are removed from total feature sets by employing forward feature selection method during training. Employing feature selection technique, the total feature sets to be given to the SVM is decreased, which in turn makes it fast and simplifies the process. The optimal feature data set with the testing data are then given to the trained SVM-D and SVM-C technique for prediction purpose. The output of SVM is either ' 0 ' or ' 1 ' denoting healthy phase or faulted phase. For each of these faults, samples of the positive-sequence component phase angle for full cycle duration have been given at the input side of SVM. The SVM-D resultant output indicates whether the corresponding section is involved with fault or not. The SVM-C resultant output indicates whether the corresponding phase is involved with fault or not.

\section{RESULTS AND DISCUSSION}

The developed support vector machine (SVM) solutions have been tested thoroughly with the help of MATLAB program. When there is healthy, the output of both SVM-D and SVM-C will be 0 values. If faults occur, the SVM-D response starts adjusting to 1, 2, and 3 depending on the section 1, section 2 and section 3 faults, respectively and SVM-C response starts adjusting to 1 during SPTS faults. The enactment of SVM-D and SVM-C for shunt faults with changing numerous fault locations, numerous fault resistances and numerous fault types is summarized. The SVM-D and SVM-C responses for all cases in Table 2 and the reach setting and accuracy of these cases are above $99.986 \%$. It is evident that the SVM method provides satisfactory enactment of faulted line discrimination, and faulty phase identification for all the samples. 
Table 2 SVM-D and SVM-C results for all cases

\begin{tabular}{|c|c|c|c|c|c|c|c|c|c|c|c|c|c|}
\hline $\begin{array}{l}\text { Parameter } \\
\text { Varied }\end{array}$ & Type & $\mathrm{L}(\mathrm{km})$ & FIA $\left(^{\circ}\right)$ & $\mathrm{R}(\Omega)$ & Section & SVM-D & \multicolumn{7}{|c|}{ SVM-C } \\
\hline \multirow{4}{*}{$\begin{array}{l}\text { Fault type is changing } \\
\text { and L, FIA, R and } \\
\text { Section are fixed }\end{array}$} & $\mathrm{Eg}$ & 21 & 45 & 10 & 1 & 1 & 0 & 0 & 0 & 0 & 1 & 0 & 1 \\
\hline & $\mathrm{ABg}$ & 21 & 45 & 10 & 1 & 1 & 1 & 1 & 0 & 0 & 0 & 0 & 1 \\
\hline & $\mathrm{ABCg}$ & 21 & 45 & 10 & 1 & 1 & 1 & 1 & 1 & 0 & 0 & 0 & 1 \\
\hline & $\mathrm{ABCDg}$ & 21 & 45 & 10 & 1 & 1 & 1 & 1 & 1 & 1 & 0 & 0 & 1 \\
\hline \multirow{6}{*}{$\begin{array}{l}\mathrm{L} \text { is changing } \\
\text { and Fault type, FIA, R } \\
\text { and Section are fixed }\end{array}$} & $\mathrm{CD}$ & 12 & 90 & 30 & 2 & 2 & 0 & 0 & 1 & 1 & 0 & 0 & 0 \\
\hline & $\mathrm{CD}$ & 26 & 90 & 30 & 2 & 2 & 0 & 0 & 1 & 1 & 0 & 0 & 0 \\
\hline & $\mathrm{CD}$ & 34 & 90 & 30 & 2 & 2 & 0 & 0 & 1 & 1 & 0 & 0 & 0 \\
\hline & $\mathrm{CD}$ & 56 & 90 & 30 & 2 & 2 & 0 & 0 & 1 & 1 & 0 & 0 & 0 \\
\hline & $\mathrm{CD}$ & 61 & 90 & 30 & 2 & 2 & 0 & 0 & 1 & 1 & 0 & 0 & 0 \\
\hline & $\mathrm{CD}$ & 75 & 90 & 30 & 2 & 2 & 0 & 0 & 1 & 1 & 0 & 0 & 0 \\
\hline \multirow{7}{*}{$\begin{array}{l}\text { FIA is changing } \\
\text { and Fault type , L, R } \\
\text { and Section are fixed }\end{array}$} & $\mathrm{BFg}$ & 74 & 50 & 40 & 3 & 3 & 0 & 1 & 0 & 0 & 0 & 1 & 1 \\
\hline & $\mathrm{BFg}$ & 74 & 120 & 40 & 3 & 3 & 0 & 1 & 0 & 0 & 0 & 1 & 1 \\
\hline & $\mathrm{BFg}$ & 74 & 160 & 40 & 3 & 3 & 0 & 1 & 0 & 0 & 0 & 1 & 1 \\
\hline & $\mathrm{BFg}$ & 74 & 200 & 40 & 3 & 3 & 0 & 1 & 0 & 0 & 0 & 1 & 1 \\
\hline & $\mathrm{BFg}$ & 74 & 240 & 40 & 3 & 3 & 0 & 1 & 0 & 0 & 0 & 1 & 1 \\
\hline & $\mathrm{BFg}$ & 74 & 290 & 40 & 3 & 3 & 0 & 1 & 0 & 0 & 0 & 1 & 1 \\
\hline & $\mathrm{BFg}$ & 74 & 330 & 40 & 3 & 3 & 0 & 1 & 0 & 0 & 0 & 1 & 1 \\
\hline \multirow{5}{*}{$\begin{array}{l}\mathrm{R} \text { is changing } \\
\text { and } \mathrm{L} \text {, Fault type, FIA } \\
\text { and Section are fixed }\end{array}$} & $\mathrm{DEF}$ & 92 & 135 & 15 & 1 & 1 & 0 & 0 & 0 & 1 & 1 & 1 & 0 \\
\hline & DEF & 92 & 135 & 30 & 1 & 1 & 0 & 0 & 0 & 1 & 1 & 1 & 0 \\
\hline & $\mathrm{DEF}$ & 92 & 135 & 45 & 1 & 1 & 0 & 0 & 0 & 1 & 1 & 1 & 0 \\
\hline & DEF & 92 & 135 & 60 & 1 & 1 & 0 & 0 & 0 & 1 & 1 & 1 & 0 \\
\hline & DEF & 92 & 135 & 80 & 1 & 1 & 0 & 0 & 0 & 1 & 1 & 1 & 0 \\
\hline \multirow{3}{*}{$\begin{array}{l}\text { Section is changing } \\
\text { and L, Fault type, FIA, } \\
\mathrm{R} \text { are fixed }\end{array}$} & $\mathrm{ABDEFg}$ & 68 & 315 & 50 & 3 & 3 & 1 & 1 & 0 & 1 & 1 & 1 & 0 \\
\hline & $\mathrm{ABDEFg}$ & 68 & 315 & 50 & 2 & 2 & 1 & 1 & 0 & 1 & 1 & 1 & 0 \\
\hline & ABDEFg & 68 & 315 & 50 & 3 & 3 & 1 & 1 & 0 & 1 & 1 & 1 & 0 \\
\hline
\end{tabular}

\section{CONCLUSION}

Fault protection in SPTS is a very important issue in nowadays. A protective relaying technique based on SVM is proposed in this paper with reach setting up to $99.986 \%$ in both reverse \& forward paths of SPTS. Two different SVM have been developed faulted line discrimination and faulty phase identification in time domain. The positive-sequence component phase angle and Haar wavelet currents are prerequisite for SVM. It is worthy to mention here that the suggested SVM offers excellent accuracy for both reverse \& forward paths also using only middle two buses data. Furthermore, its robustness against numerous fault locations, numerous fault resistances and numerous fault types is also studied. It was confirmed that for all cases, the reach setting of fault relaying is much superior to other methods.

\section{REFERENCES}

[1] S. S. Venkata, W. C. Guyter, J. Kondragunta, and N. B. Butt, "EPPC - A computer program for six-phase transmission line design," IEEE Transactions on Power Apparatus and Systems, vol. 101, no. 7, pp. 1859-1869, 1982, doi: 10.1109/TPAS.1982.317457.

[2] J. R. Stewart, L. J. Oppel, G. C. Thomas, T. F. Dorazio, and M. T. Brown, "Insulation coordination, environmental and system analysis of existing double circuit line reconfigured to six-phase operation," IEEE Transactions on Power Delivery, vol. 7, no. 3, pp. 1628-1633, 1992, doi: 10.1109/61.141883.

[3] L. Oppel, and E. Krizauskas, "Evaluation of the performance of line protection schemes on the NYSEG six phase transmission system," IEEE Transactions on Power Delivery, vol. 14, no. 1, pp. 110-115, 1990, doi: $10.1109 / 61.736697$.

[4] A. Apostolov, and W. George, "Protecting NYSEG's six-phase transmission line," IEEE computer applications in power, vol. 5, no. 4, pp. 33-36, 1992, doi: 10.1109/67.160044.

[5] K. Ebha, J. Anamika, A. S. Thoke, J. Abhinav, and G. Subhojit, "Detection and classification of faults on six phase 
transmission line using ANN," 2011 2nd International Conference on Computer and Communication Technology (ICCCT-2011), 2011, pp. 100-103, doi: 10.1109/ICCCT.2011.6075177.

[6] K. Ravi, K. Ebha, Y. Anamika, and A. S. Thoke, "Fault classification of phase to phase fault in six phase transmission line using haar wavelet and ANN," 2014 International Conference on Signal Processing and Integrated Networks (SPIN), India, 2014, pp. 5-8, doi: 10.1109/SPIN.2014.6776911.

[7] A. N. kumar, and M. Chakravarthy, "Simultaneous fault classification and localization scheme in six phase transmission line using artificial neural networks," Journal of Advanced Research in Dynamical \& Control Systems, vol. 10, no. 3, pp. 342-349, 2018.

[8] A. Naresh, and M. Chakravarthy, "Fuzzy inference system based distance estimation approach for multi location and transforming phase to ground faults in six phase transmission line," International Journal of Computational Intelligence Systems, vol. 11, no. 1, pp. 757-769, 2018, doi: 10.2991/ijcis.11.1.58.

[9] G. Kapoor and A. Yadav, "A Single-Terminal Hybrid Scheme for Six-Phase Transmission Line Protection," 2020 IEEE International Conference on Power Electronics, Drives and Energy Systems (PEDES), 2020, pp. 1-6, doi: 10.1109/PEDES49360.2020.9379377.

[10] K. S. Sunil, K. Ebha, and G. Subhojit, "A hybrid wavelet-APSO-ANN-based protection scheme for six-phase transmission line with real-time validation," Neural Computing and Applications, vol. 31, pp. 5751-5765, 2018, doi: 10.1007/s00521-018-3400-x.

[11] K. S. Sunil, K. Ebha, G. Subhojit, and K. M. Dusmanta, "Enhancing the reliability of six phase transmission line protection using power quality informatics with real time validation," International Transactions on Electrical Energy Systems, vol. 29, no. 9, 2019, Art. no. e12048, doi: 10.1002/2050-7038.12048.

[12] K. Ebha, Y. Anamika, and S. T. Aniruddha, "A new single-ended artificial neural network-based protection scheme for shunt faults in six-phase transmission line," International Transactions on Electrical Energy Systems, vol. 25, no. 7, pp. 1257-1280, 2015, doi: 10.1002/etep.1901.

[13] K. Ebha, V. Khushaboo, and G. Subhojit, "An improved fault detection classification and fault location scheme based on wavelet transform and artificial neural networks for six phase transmission line using single end data only," Springer Plus, vol. 4, 2015, Art. No. 551, doi: 10.1186/s40064-015-1342-7.

[14] K. Mishra, and A. Yadav, "A single ended fuzzy based directional relaying scheme for transmission line compensated by fixed series capacitor," International Conference on Intelligent Systems Design and Applications, vol. 941, 2020, pp. 749-759, doi: 10.1007/978-3-030-16660-1_73.

[15] A. N. kumar, Ch Sanjay, and M. Chakravarthy, "A single-end directional relaying scheme for double-circuit transmission line using fuzzy expert system," Complex and Intelligent Systems, vol. 6, pp. 335-346, 2020, doi: 10.1007/s40747-020-00131-w.

[16] S. R. Samantaray, "Decision tree-based fault zone identification and fault classification in flexible AC transmissions-based transmission line," IET Generation, Transmission and Distribution, vol. 3, no. 5, pp. 425-436, 2009, doi: 10.1049/iet-gtd.2008.0316.

[17] Y. Anamika, D. Yajnaseni, and V. Ashok, "ANN based directional relaying scheme for protection of korba-bhilai transmission line of chhattisgarh state," Protection and Control of Modern Power Systems, vol. 1, no. 1, pp. 1-17, 2016, doi: 10.1186/s41601-016-0029-6.

[18] K. Ebha, V. Khushaboo, and G. Subhojit, "A modular neuro- wavelet based non-unit protection scheme for zone identification and fault location in six phase transmission line," Neural Computing and Applications, vol. 28, no. 6, pp. 1369-1385, 2017, doi: 10.1007/s00521-016-2566-3.

[19] A. N. kumar, Ch. Sanjay, and M. Chakravarthy, "Mamdani fuzzy expert system based directional relaying approach for six phase transmission line," International Journal of Interactive Multimedia and Artificial Intelligence, vol. 6 , no. 1, pp. 41- 50, 2020, doi: 10.9781/ijimai.2019.06.002.

[20] P. K. Dash, S. R. Samantaray, and G. Panda, "Fault classification and section identification of an advanced series compensated transmission line using support vector machine," IEEE Transactions on Power Delivery, vol. 22, pp. 67-73, 2007, doi: 10.1109/TPWRD.2006.876695.

[21] S. Aleena, and Y. Anamika, "Directional relaying using support vector machine for double circuit transmission lines including cross-country and inter-circuit faults," International Journal of Electrical Power and Energy Systems, vol. 81, pp. 254-264, 2016, doi: 10.1016/j.ijepes.2016.02.034.

[22] P. Ray, S. R. Arya, and D. P. Mishra, "Intelligence Scheme for fault location in a combined overhead transmission line \&underground cable," International Journal of Emerging Electric Power Systems, vol. 19, no. 5, pp. 1-18, 2018, doi: 10.1515/ijeeps-2017-0277.

[23] D. P. Mishra, and P. Ray, "Fault detection, location and classification of a transmission line," Neural Computing and Applications, vol. 30, no. 5, 1377-1424, 2018, doi: 10.1007/s00521-017-3295-y.

[24] P. Ray, and D. P. Mishra, "Support vector machine-based fault classification and location of a long transmission line," Engineering Science and Technology, an International Journal, vol. 19, no. 3, pp. 1368-1380, 2016, doi: 10.1016/j.jestch.2016.04.001.

[25] P. Ray, and D. P. Mishra, "Application of extreme learning machine for underground cable fault location," International Transactions on Electrical Energy Systems, vol. 25, no. 12, pp. 3227-3247, 2015, doi: 10.1002/etep.2032. 